\title{
A Review of the Impact of Market Orientation on Organizational Performance
}

\author{
RongJun $\mathrm{Ni}^{1, \mathrm{a}}$, Min Qian ${ }^{1, \mathrm{~b}}$ \\ ${ }^{1}$ School of Economics and Management, Nanjing University of Science and Technology, Nanjing \\ 210094, China \\ a13855441216@163.com, '1684356170@qq.com
}

Keywords: market orientation; organizational performance; organizational strategy

\begin{abstract}
Market orientation is one of the major research areas for the development of strategic marketing in the past two decades. Since the early 1990s, the main goal of market-oriented research has been the relationship between market orientation and organizational performance. This paper reviews the domestic and foreign scholars' research results on the relationship between market orientation and organizational performance. The results show that the existing research can be divided into three types: the first one is that the market orientation directly affects the organizational performance; the second is the relationship between the organizational performance and the market orientation; The influence of market orientation on organizational performance exists in the role of intermediary variables and regulatory variables. Third, market orientation has no direct impact on organizational performance.
\end{abstract}

\section{Introduction}

For a long time, the research on the relationship between market orientation and organizational performance has been one of the focuses of academia at home and abroad. With the accelerating process of internationalization of enterprises and the intensification of market competition, how to improve the organizational performance through the implementation of targeted marketing strategies has become an important issue for business operators. As one of the important strategies of modern marketing practice, market orientation can promote the continuous success of the enterprise and help the organization formulate a better strategy. Therefore, sorting out and analyzing the research results of the relationship between market orientation and organizational performance is also conducive to the further development of research in this field.

\section{Related Concepts Overview}

\subsection{Market-oriented concepts and measurement}

\subsection{1 market-oriented meaning}

At present, there is not yet a broadly accepted and accepted definition of market orientation in academia. However, from the existing literature, the main researchers in this field mainly focus on two different perspectives: behavioral perspective and cultural perspective Different definitions of market orientation.

Some scholars define market orientation from the behavioral perspective. Kohli defined market orientation in 1990 as "a series of specific corporate actions and activities that are a series of behaviors that generate market intelligence based on current and future customer needs and disseminate and diffuse throughout the organization, But also the process of cooperation and feedback.

Still other scholars define market orientation from the perspective of culture. Narver and Slater studied and analyzed the market orientation from another perspective - the organizational culture in the enterprise. They define market orientation as "an organizational culture that continually stimulates all employees in an organization to take the actions necessary to create and deliver excess value to their customers and achieve superior organizational performance." 


\subsubsection{Market-oriented measurement}

Differences in market-oriented definitions have led to different scales of measurement of the market-oriented concept. Narver and Slater originally designed five dimensions of customer-oriented, competitor-oriented, inter-functional coordination, focusing on long-term and focused profitability, but the empirical test found that the reliability coefficient of focusing on long-term and profitability was lower than the acceptance As a result, the scope was excluded, resulting in a MKTOR questionnaire with Rexroth grade 7 on 15 questions. Deshpande, Farley, and Webster devised a DFW scale consisting of nine items that basically covered both the customer-oriented and the competitor-oriented aspects of the MKTOR scale and was considered a variant of the MKTOR scale Simplify, the same spread widely used .

\subsection{The concept of organizational performance and measurement}

\subsubsection{The meaning of organizational performance}

Ford and Schellenberg reviewed three previous studies and summarized three ways of defining organizational performance in 1992. The first is the goal of law, the use of companies to achieve the desired goals to determine the extent of organizational performance; the second is the system of resources law, from the enterprise owned by the scarcity of valuable resources and resources from the perspective of the definition; the third is the ingredient method, With the staff and business and employee interaction between the performance of inspection.

\subsubsection{Measurement of organizational performance}

The measurement of organizational performance can generally be divided into three perspectives. One is the measurement of single and multiple indicators. The second is the measurement of financial and non-financial indicators. The third is the measurement of objective and subjective indicators.

\section{An Empirical Study of Market Orientation on Organizational Performance}

This paper reviews and concludes the domestic and international empirical research on the relationship between market orientation and organizational performance, and finds that the research results can be divided into three categories: First, the market orientation has a direct impact on organizational performance; second, Organizational performance mediates between variables or adjust the role of variables; third is the market orientation has no direct impact on organizational performance. The following describes the market-oriented and organizational performance of the three relations between the research results were introduced.

\subsection{Market-oriented direct impact on organizational performance}

Most research findings found a positive correlation between market orientation and organizational performance. Most of the research results on the direct impact of market orientation on organizational performance come from foreign countries. Some scholars in our country also study the direct relationship between the two and get the research results.

\subsubsection{Overseas research results on the market-oriented direct impact on organizational performance}

Foreign scholars on market-oriented and organizational performance of the research results include different sizes of enterprises and different industries and enterprises. Jaworski and Kohli, using 222 strategic institutions in 102 US companies as a sample, and using the MARKOR scale to measure market orientation, found that market orientation had a positive effect on organizational performance.

A large number of studies have shown that market orientation has a direct impact on organizational performance. Table 1 shows some other research results on the direct impact abroad. 
Table 1 Foreign research results on the market-oriented direct impact on organizational performance

\begin{tabular}{|l|l|}
\hline \multicolumn{1}{|c|}{ Author and age } & \multicolumn{1}{|c|}{ Analysis conclusion } \\
\hline $\begin{array}{l}\text { Narver S Slater } \\
\text { (1990) }\end{array}$ & $\begin{array}{l}\text { There is a non-linear relationship between market } \\
\text { orientation and organizational performance }\end{array}$ \\
\hline Pelham(2000) & $\begin{array}{l}\text { Market orientation has a significant positive impact on } \\
\text { marketing effectiveness, share growth and profitability }\end{array}$ \\
\hline Wood (2002) & $\begin{array}{l}\text { There is a significant positive correlation between market } \\
\text { orientation and organizational performance }\end{array}$ \\
\hline Deshpande(2004) & $\begin{array}{l}\text { Market orientation has a positive direct effect on } \\
\text { performance }\end{array}$ \\
\hline Brettel, Claas(2006) & $\begin{array}{l}\text { Market orientation has a significant positive effect on } \\
\text { performance }\end{array}$ \\
\hline O'Cass, Ngo(2007) & $\begin{array}{l}\text { Market orientation has a significant positive impact on } \\
\text { overall brand performance }\end{array}$ \\
\hline Morgan (2009) & $\begin{array}{l}\text { Market-oriented enterprises have a direct impact on the } \\
\text { return on assets }\end{array}$ \\
\hline Kwon(2010) & Market orientation has an important effect on performance \\
\hline
\end{tabular}

3.1.2 domestic market-oriented research directly affects the performance of the research results

Domestic market-oriented research on organizational performance is relatively small. Fan Xiao-ping in 2003 through the empirical analysis of small and medium export enterprises in Zhejiang Province, found that market-oriented export performance (except financial performance) has a positive role in promoting; Yu Jianliang and Qing Shuo to Changsha, Hunan commercial banks as a sample of commercial Market-oriented banking, empirical research on the relationship between innovation and performance.

\subsection{The impact of market orientation on organizational performance There is an intermediary or regulatory role}

As scholars find inconsistencies in the conclusions of the research on the relationship between market orientation and organizational performance, scholars are urged to explore the reasons for this. Some scholars believe that in the relationship between market orientation and organizational performance, there may be intermediary variables play a role in the mechanism of the two, or there are regulatory variables to adjust the relationship between market orientation and organizational performance, so that the conclusions of the study Inconsistent phenomenon.

\subsubsection{Market-oriented research on the impact of organizational performance through intermediary variables}

While studying the influence of the direct relationship between market orientation and organizational performance, many foreign scholars have conducted extensive research on whether there exists an intermediary role between market orientation and organizational performance. Most of them believe that market orientation can enhance the company's ability to innovate, speed up the development of new products, improve customer satisfaction and enhance the performance of enterprises, thus affecting the performance of enterprises.In addition, some scholars have suggested that organizational learning and customer response are also mediators between market orientation and organizational performance. Oakley regards customer reaction as an intermediary variable between market orientation and organizational performance and confirms that customer response plays an intermediary role in the relationship between market orientation and performance.

In China, some scholars also study the existence of intermediary variables between market orientation and organizational performance. In 2006, Yang Zhi and Liu Xinyan conducted a survey on 110 enterprises in five provinces in eastern and central China, and found that organizational learning and marketing innovation have a complete mediating effect on the relationship between market orientation and organizational performance. 


\subsubsection{The impact of market orientation on organizational performance is subject to regulatory variables}

While studying the influence of the intermediary variable between market orientation and organizational performance, some scholars think about the function of market-oriented influence on organizational performance, and do some related research. Lonial and Raju's 2001 study found that environmental uncertainty has a regulatory effect on the relationship between market orientation and organizational performance.

\subsection{Market Orientation has no direct impact on organizational performance}

In the study of the impact of market orientation and organizational performance, some studies find that market orientation has no direct effect on organizational performance. Frishammar, Andersson conducted an empirical study of 188 Swedish SMEs in 2009 and found that market orientation in these firms had only a limited impact on their international performance, likely due to the applicability of traditional market-based measures to SMEs Problem.

The reason for the conclusion that market orientation has no effect on organizational performance may be due to different types of commodity management, different performance indicators, including different financial indicators, different financial indicators and non-financial indicators, and different market-oriented types.

\section{Summary}

After sorting out and analyzing the domestic and international market-oriented empirical research on organizational performance, we understand that it still can not reach a unanimous conclusion on the relationship between the two. Whether it is market-oriented or organizational performance are hot topics in academia. Therefore, it is of great theoretical and practical significance to continue to explore the relationship between the two and to explore the mechanism of market orientation on organizational performance in the future.

\section{References}

[1]Ruekert .R.w, Developing a Market Orientation :An Organizational Strategy Perspectives [J].International Journal of Research in Marketing,1992, 9 (I):225-245.

[2]K Matsuno ,JT Mentzer. The Effect of Strategy Type on Market Orientation-Performance Relationship[J]. Journal of Marketing, 2000 , 64 (4) :1-16.

[3]Kohli, A. K., Jaworski, B. J., Kumar, A.. MARKOR: A Measure of Market Orientation. Journal of Marketing Research, 1993, 30(4): 467-477.

[4]YU Jian-liang, QING Shuo. Two Market-Oriented Approaches and Comparative Studies [J] .Business and Technology in the Coast, 2005 (12): 165-165.

[5]Frishammar,Andersson. The overestimated role of strategic orientations for international performance in smaller firms ”[J].Journal of International Entrepreneurship, 2009,7(1): 57- 77. 